exposed employees. Furthermore, given that many asbestosis cases progress to lung cancers, the amount of compensation solely from the asbestosis disability appears inadequate. It is suggested that the Indonesian Manpower Ministry review the compensation system to include follow-up and screening for malignancies, their treatment, and related disabilities.

\section{RESPIRABLE CRYSTALLINE SILICA (RCS) EXPOSURE MONITORING, HEALTH SURVEILLANCE AND HAZARD COMMUNICATION IN PREVENTING SILICOSIS AMONG STONE WORKERS}

${ }^{1}$ Mahinda Seneviratne*, ${ }^{2}$ Kiran Shankar, ${ }^{1}$ Phillip Cantrell, ${ }^{1}$ Aklesh Nand. ${ }^{1}$ Hygiene and Toxicology, SafeWork NSW, Baulkham Hills, NSW, Australia: ${ }^{2}$ Chemical Analysis Branch, TestSafe Australia, Thornleigh, NSW, Australia

\subsection{6/oemed-2018-ICOHabstracts. 1256}

Introduction Exposure to respirable crystalline silica (RCS) causes the serious lung disease silicosis among many workers globally. There was renewed attention to silicosis when new cases were reported among workers involved in the use of engineered stone in bench top manufacturing.

Methods A regulatory verification program was conducted in the State of New South Wales in Australia to investigate exposure of stone workers to RCS, compliance with health surveillance requirements and to improve communication of the health hazards of RCS to poorly informed workers. Airborne RCS exposures were measured in the workers' breathing zones using cyclone sampling heads for particle size selection. X-ray diffraction (XRD) analysis was performed to assess the silica content of the respirable dust. Compliance with national Work Health and Safety Regulations on health monitoring for RCS exposure, which include annual chest $\mathrm{x}$-rays, were verified at each workplace. Hazard information was developed in consultation with workers and small group education conducted to improve their awareness and knowledge on silica hazards.

Result The Australian Workplace Exposure Standard (WES) of $0.1 \mathrm{mg} / \mathrm{m}^{3}$ for RCS was exceeded in many personal air samples. Workers who had worked in the industry for many years had not undergone a complete health monitoring including chest x-ray and spirometry.

Discussion The WES for RCS is being reviewed and lowered to $0.025 \mathrm{mg} / \mathrm{m}^{3}$ in some countries whilst some industries raise concerns on whether they can practicably achieve this limit. The reliance on chest $\mathrm{x}$-rays and spirometry in the early detection of silicosis has also been queried by numerous case studies and by the Australian inquiry into coal worker pneumoconiosis.

We report our findings and explore whether technological changes result in high RCS exposures and a re-emergence of silicosis among poorly informed workforces. Developing professional collaboration among different disciplines to prevent this deadly disease will be discussed.

\section{GB SILICOSIS CASES FOLLOWING A RECENT GUIDANCE UPDATE}

'David Fishwick*, ${ }^{2}$ Sue Matthews, ${ }^{2}$ Mohammed Kamil, ${ }^{1}$ Chris Barber. ${ }^{1}$ Centre for Workplace Health, HSE, Buxton, Derbyshire, UK; ${ }^{2}$ Department of Radiology, Northern General Hospital, STH NHS Foundation trust, Sheffield, UK

10.1136/oemed-2018-ICOHabstracts.1257
Introduction Silicosis still occurs globally as a consequence of exposure to respirable crystalline silica (RCS). The Health and Safety Executive (HSE) regulates the workplace in Great Britain, and recently updated its silica based guidance relating to health surveillance. We report our early experience dealing with cases referred to our clinical service following this update.

Methods Our Occupational Lung Disease service runs a weekly multidisciplinary team (MDT) meeting. Following the relatively recent updated silica guidance issued by HSE, our clinical service offered to accept referrals of workers exposed to RCS who have undergone health surveillance at work. This would normally have consisted of lung function testing and a chest X Ray (CXR). A consultant respiratory physician and a radiologist, the latter reading to International Labour Organisation (ILO) radiology standards, discussed each case referred to the service at the MDT.

Result To date, 36 workers have been referred with potentially abnormal radiology. The mean age of this group of workers was 55 years (range 23-75), 8 were female. Twenty workers (56\%), with a mean age of 55 years (range 35-75) and a mean duration of RCS exposure of 25.2 years (range 9-50), had an ILO grade recorded for the presence of small opacities on their CXR which were thought to be potentially consistent with silicosis. A further 11 were identified to have an incidental, not silica related, radiological abnormality and 5 had normal radiology.

Discussion Since HSE has refreshed and updated its silica based workplace guidance, workers have been identified with potentially abnormal chest $\mathrm{x}$ rays. Of those referred to us, a substantial proportion was identified to have small opacities consistent with silicosis. Workplaces must continue to risk assess all tasks potentially associated with RCS exposure, and subsequently intervene to reduce these exposures.

\section{FARMER'S LUNG DISEASE IN A COHORT OF BRITISH AGRICULTURAL WORKERS}

Chris Barber*, David Fishwick, Anne-Helen Harding. Centre for Workplace Health, HSE, Buxton, Derbyshire, UK

\subsection{6/oemed-2018-ICOHabstracts. 1258}

Introduction Farmer's Lung Disease (FLD) is the oldest recognised form of occupational hypersensitivity pneumonitis (OHP) and remains one of the most commonly reported causes in Europe.The aim of this study was to provide novel data on the prevalence and demographic risk factors of FLD in a large cohort of British farm workers.

Methods Farmers were identified from the baseline survey of the PIPAH cohort (Prospective Investigation of Pesticide Applicators' Health). The demographics of workers, who selfreported a doctor diagnosis of FLD, were compared to the remainder of the cohort.

Result Questionnaire data was available for 5115 current or former farmers, representing a cumulative total of over 210,000 years of farming practice. 26 farmers self-reported a diagnosis of FLD, representing a cohort prevalence of $\sim 5$ per 1000. Those with FLD were all male, and were older, more likely to be involved in animal production and less likely to be involved in crop production only than those without FLD. Those with and without FLD did not differ in respect of years lived or worked on a farm, or their smoking status. 
Median age of FLD diagnosis was 35 (IQR 25-43, range 16-62), with a median latent period from first farm exposure of 28 years (IQR 20-42).

Discussion The prevalence of FLD in this British cohort (representing over $1 \%$ of British farmers) was in keeping with that reported from other countries. Age of diagnosis was very variable, with the majority of those affected having never smoked. Although most had worked on a mixture of farm types, workers with FLD were more likely to report only having lived on an animal versus cereal production farm

\section{EXPOSURE TO CRYSTALLINE SILICA AND LUNG FUNCTION IN OUTDOOR ROCK DRILLERS}

Bente Ulvestad, Nils Petter Skaugset, Berit Bakke, Kari Dahl, Dag Gunnar Ellingsen. National Institute Of Occupational Health, Oslo, Norway

\subsection{6/oemed-2018-ICOHabstracts.1259}

Introduction A number of tasks in heavy construction generate crystalline silica dust, which is a significant contributor to occupational mortality and morbidity. When a new heavy construction site is established, first excavators come to clear the soil. Thereafter holes are drilled to prepare for blasting. There is a lack of knowledge regarding exposure levels of dust and crystalline silica among rock drillers and blasting workers generated by these work tasks. Exposure to dust and crystalline silica are suggested to cause obstructive and restrictive lung changes.

Methods The study is designed as a two years follow-up of 132 rock drillers and 50 referents (administrative personnel) working in the same construction companies, but without airborne occupational exposure. All subjects were examined with lung function tests and blood was collected during the winter $2015 / 2016$. They will be re-examined in 2017/2018. Pneumoproteins and markers of inflammation are currently being analysed.

Eighty-three rock drillers using different drilling rigs carried air-sampling equipment for the determination of respirable dust and crystalline silica.

Result Preliminary results show: The exposure to dust and crystalline silica in the respirable aerosol fraction ranged from 0.01 to $2.91 \mathrm{mg} / \mathrm{m}^{3}$, and from 0.002 to $0.45 \mathrm{mg} / \mathrm{m}^{3}$, respectively, depending on type of drilling equipment in use. Workers using drill rigs with feed mounted operation panels were most highly exposed.

Compared with the referents at baseline the rock drillers had significantly lower forced vital capacity (FVC)\% predicted $(\mathrm{p}=0.012)$ and forced expiratory volume in one second $\left(\mathrm{FEV}_{1}\right) \%$ predicted $(\mathrm{p}=0.001)$. The decline in $\mathrm{FEV}_{1} / \mathrm{FVC}$ (Tiffeneau index) was associated with years of exposure $(p=0.017)$ and smoking (pack years) $(p=0.02)$. The serum concentration of CRP was comparable between the two groups.

Discussion Exposure to crystalline silica during rock drilling may have negative impact on the lung function.

\section{CHEST CT SCANNING IN THE SCREENING, SURVEILLANCE, AND DIAGNOSIS OF OCCUPATIONAL LUNG DISEASES}

Rafael E de la Hoz. Icahn School of Medicine at Mount Sinai, New York, NY, USA
Aim of special session Advances with chest CT scanning and CT scan-based lung cancer screening are changing the way diagnosis and screening for occupational lung diseases are conducted. We plan to review existing methodologies and experience-based emerging strategies.

Thomas Kraus, MD, $\mathrm{PhD}^{1}$, Kurt G. Hering, $\mathrm{MD}^{2}$, Narufumi Suganuma, $\mathrm{MD}, \mathrm{PhD}^{3}$, and Rafael E. de la Hoz, MD, $\mathrm{MPH}, \mathrm{MSc}^{4}$

${ }^{1}$ RWTH Aachen, Aachen, Germany

${ }^{2}$ Knappschafstkrankenhaus Dortmund, Dortmund, Germany

${ }^{3}$ Kochi Medical School, Kochi University, Nankoku 7838505, Japan

${ }^{4}$ Icahn School of Medicine at Mount Sinai, New York, NY, USA

\begin{tabular}{|l}
\hline $1677 a$ \\
INTERNATIONAL CLASSIFICATION OF HRCT FOR \\
OCCUPATIONAL AND ENVIRONMENTAL RESPIRATORY \\
DISEASES: DESCRIBING NON-MALIGNANT AND \\
MALIGNANT ASBESTOS RELATED DISEASES
\end{tabular}

Narufumi Suganuma. Kochi Medical School, Kochi University, Nankoku, Japan

10.1136/oemed-2018-ICOHabstracts. 1261

ILO Classification of Radiograph of Pneumoconioses (ILO/ICRP) has played an important role in screening and surveillance of pneumoconiosis among dust exposed workers worldwide. As the ILO/ICRP has semi-quantitative scheme, it allows objective and standardised recording of radiographic findings on chest radiographs of workers. The International Classification of HRCT for Occupational and Environmental Respiratory Diseases (ICOERD) have been proposed from International Expert Team consists of researchers from 7 countries, based on the consensus report at the Helsinki Meeting for Asbestos related diseases in 2000. The ICOERD system covers all aspect of Occupational and Environmental Respiratory Diseases, starting with six parenchymal findings and two pleural abnormalities. Parenchymal findings include well-defined rounded opacities, irregular opacities, inhomogeneous attenuation, honeycombing, emphysema and large opacities. Irregular opacities include intralobular opacities and interlobular opacities, the former include centrilobular opacities suggestive of inhalation diseases. The ICOERD classifies these parenchymal findings in 4-point-scale, grading 6 lungs zones. Consequently, the final grade for each of the parenchymal findings sums up to 18point-scale. Pleural abnormalities cover pleural thickening of parietal and/or visceral types. Width and extent of pleural thickening is graded in 4-point-scale. As multi-detector CT can be used for screening of non-malignant and malignant diseases, the ICOERD added supplemental coding for mesothelioma, which allows standardised recording of findings suggestive of mesothelioma. CT findings of unilateral pleural effusion, nodular pleural thickening, mediastinal pleural thickening, interlobar fissure thickening, diminished lung, contracted hemithorax should be noticed when reviewing CT scans of asbestos-exposed persons.

\section{$1677 \mathrm{~b}$ EXPERIENCE WITH THE ICOERD CLASSIFICATION IN WTC LUNG DISEASES}

Rafael E de la Hoz. Icahn School of Medicine at Mount Sinai, New York, NY, USA

10.1136/oemed-2018-ICOHabstracts. 1262 